\title{
Mixed Ionic-Electronic YSZ/Ni Composite for SOFC Anodes with High Electrical Conductivity
}

\author{
Fabio C. Fonseca, ${ }^{\mathrm{a}, \mathrm{z}}$ Daniel Z. de Florio, ${ }^{\mathrm{b}}$ Vincenzo Esposito, ${ }^{\mathrm{c}, *}$ \\ Enrico Traversa, ${ }^{\mathrm{c}, * *}$ Eliana N. S. Muccillo, ${ }^{\text {a, } * *}$ and Reginaldo Muccillo ${ }^{\mathrm{a}, * *}$ \\ ${ }^{a}$ Instituto de Pesquisas Energéticas e Nucleares, 05508-170 São Paulo, SP, Brazil \\ ${ }^{b}$ Instituto de Química, UNESP, 14801-970 Araraquara, SP, Brazil \\ ${ }^{c}$ Dipartimento di Scienze e Tecnologie Chimiche, Università degli Studi di Roma "Tor Vergata," \\ 00133 Roma, Italy
}

\begin{abstract}
The preparation of the $\mathrm{ZrO}_{2}: 8 \mathrm{~mol} \% \mathrm{Y}_{2} \mathrm{O}_{3} / \mathrm{NiO}$ (YSZ/NiO) composites by a modified liquid mixture technique is reported Nanometric NiO particles dispersed over the yttria-stabilized zirconia (YSZ) were prepared, resulting in dense sintered specimens with no solid solution formation between the oxides. Such a feature allowed for the electrical characterization of the composites in a wide range of relative volume fraction, temperature, and oxygen partial pressure. The main results indicate that the composites have high electrical conductivity, and the transport properties in these mixed ionic-electronic (MIEC) composites are strongly dependent on the relative volume fraction of the phases, microstructure, and temperature. These parameters should hence be taken into consideration for the optimized design of MIEC composites for electrochemical applications. In this context, the composite was reduced under $\mathrm{H}_{2}$ for the preparation of high-conductivity YSZ/Ni cermets for use as solid oxide fuel cell anode material with relatively low metal content.

(C) 2005 The Electrochemical Society. [DOI: 10.1149/1.2149312] All rights reserved.
\end{abstract}

Manuscript submitted August 19, 2005; revised manuscript received October 3, 2005. Available electronically December 30,2005

Mixed ionic-electronic conductors (MIECs) have attracted a great deal of attention due to the variety of possible applications and interesting electrical properties. ${ }^{1-3}$ These materials are thought to be used in high-temperature electrochemical devices such as gas separation membranes and solid oxide fuel cell (SOFC) electrodes. ${ }^{2,3}$ The mixed conduction can be either an intrinsic property of singlephase materials (like cerium oxide and some rare-earth manganites) or a result of the mixture of ionic and electronic conductors (MIEC composite). ${ }^{3}$ The main advantage of the MIEC composite is the possibility for tailoring the properties according to optimized parameters for a specific application. ${ }^{3}$ In this context, the SOFC anode is the cermet $\mathrm{ZrO}_{2}: \mathrm{Y}_{2} \mathrm{O}_{3} / \mathrm{Ni}$ (YSZ/Ni), produced by the reduction of the precursor composite $\mathrm{ZrO}_{2}: \mathrm{Y}_{2} \mathrm{O}_{3} / \mathrm{NiO}(\mathrm{YSZ} / \mathrm{NiO}){ }^{4}$ Both the cermet and the oxide precursor are MIEC composites and must fulfill several requirements for a high-performance SOFC. An important issue regarding this anode material is the reduction of the $\mathrm{Ni}$ volume fraction for better matching of the thermal expansion coefficient with the electrolyte, while both high electric conductivity and catalytic activity must be preserved. ${ }^{4}$

In fact, the final properties of the anode cermet are strongly dependent on the precursor composite, and various studies deal with the fabrication of the YSZ/NiO composite aiming for the production of SOFC anodes, but rather few papers report a more detailed microstructural and electrical characterization of the precursor composite. ${ }^{5-7}$ The usually high temperatures $\left(\geqslant 1500^{\circ} \mathrm{C}\right)$ reported for the densification of the composite promote the YSZ destabilization or solid solution formation due to the reaction with $\mathrm{NiO}$, resulting in a considerable reduction of the electrical conductivity. ${ }^{8-10}$ It is well known that the electrical properties of composites depend not only on the electrical properties of each phase but also are strongly influenced by microstructural features such as grain size, distribution, and morphology. The electrical properties of composite media are an important subject, and although several proposed models like percolation and effective media are usually applied, no analytical solution for this problem has been found so far. ${ }^{11,12}$ Moreover, the nature of the charge carriers and the dependence of the electrical transport properties on the microstructure, temperature, and oxygen partial pressure can be considered as important issues for electrochemical applications of MIEC composites.

Thus, in order to produce high-performance anodes for SOFCs, a

\footnotetext{
* Electrochemical Society Student Member.

** Electrochemical Society Active Member.

z E-mail: cfonseca@ipen.br
}

detailed characterization of the electrical and microstructural properties of the YSZ/NiO composite prepared by a liquid mixture technique was performed. The observed high sinterability and high electrical conductivity of the studied composites can be considered as important advantages of the liquid mixture technique when compared to the ones usually reported. The main results show that the microstructure and the ionic/electronic transference numbers of high-conductivity composites can be tuned for high-temperature electrochemical applications. Moreover, an optimized microstructure of the YSZ/NiO composite is achieved after reduction of YSZ/Ni cermets, with high electrical conductivity at relatively low $\mathrm{Ni}$ content.

\section{Experimental}

The precursor composite $(1-v)\left(\mathrm{ZrO}_{2}: 8 \mathrm{~mol} \% \mathrm{Y}_{2} \mathrm{O}_{3}\right) / v \mathrm{NiO}$ ( $\mathrm{YSZ} / v \mathrm{NiO}$ ) was prepared in the $0 \leqslant v($ vol $\%) \leqslant 100$ range and tailored to result, after reduction, in YSZ $/ v \mathrm{Ni}$ cermets with $v$ within the range for SOFC anodes. These materials were prepared by a modified liquid mixture technique and further details can be found elsewhere. ${ }^{13}$ Briefly, this technique consists of the evaporation of a dispersion of YSZ (Tosoh) powder in a solution of nickel acetate tetrahydrate (Carlo Erba) and ethanol, followed by calcination at $450^{\circ} \mathrm{C} / 5 \mathrm{~h}$ to eliminate the organic material. Scanning electron microscopy (SEM) analysis of the as-produced powders revealed that the composite powders were made of a homogenous mixture of $\mathrm{NiO}$ nanoparticles $\left(d_{\mathrm{NiO}} \approx 15 \mathrm{~nm}\right)$ with YSZ particles $\left(d_{\mathrm{YSZ}} \approx 100 \mathrm{~nm}\right) .{ }^{13}$ Pellets were formed by uniaxial pressing and sintering at $1350^{\circ} \mathrm{C}$. X-ray diffraction (XRD) data were collected in a model D8 Advance Bruker-AXS diffractometer in a BraggBrentano $\theta-2 \theta$ configuration using $\mathrm{Cu} \mathrm{K} \alpha$ radiation in the $25-85^{\circ}$ $2 \theta$ range with step size $0.02^{\circ} 2 \theta$ and $10 \mathrm{~s}$ counting time. Refinement of the XRD patterns was carried out by the Rietveld method using GSAS software and the reported Inorganic Crystal Structure Database (ICSD) no. 75316, 9866, and 44767 for YSZ, NiO, and $\mathrm{Ni}$, respectively. The microstructure of polished and fractured surfaces of sintered samples was observed by SEM. The electrical properties of the YSZ $/ v \mathrm{NiO}$ composite were studied by electrochemical impedance spectroscopy measurements $Z(\omega, T)$ carried out using a 4192A LF impedance analyzer in the temperature range $100-800^{\circ} \mathrm{C}$ and frequency range $5 \mathrm{~Hz}-13 \mathrm{MHz}$ with an applied excitation signal of $200 \mathrm{mV}$. The oxygen partial pressure $\left(p_{\mathrm{O}_{2}}\right)$ was varied in the range of $1-10^{-6} \mathrm{~atm}$ using a YSZ electrochemical oxygen pump and sensor system connected to the impedance analyzer. ${ }^{14}$ The $\mathrm{YSZ} / v \mathrm{Ni}$ cermets were produced by reducing the precursor composite by 
heat-treating at $550^{\circ} \mathrm{C}$ under $\mathrm{H}_{2}$ flow $(100 \mathrm{~mL} / \mathrm{min})$ for $5 \mathrm{~h}$. The microstructure of the cermets was characterized by XRD and SEM analysis. Standard four-probe dc electrical resistance $\rho(T)$ measurements of bar-cut cermets were performed in the temperature range $100-800^{\circ} \mathrm{C}$ under He flow using a Keithley current source and voltmeter. In all electrical measurements, $\mathrm{Pt}$ wires were attached to $\mathrm{Ag}$ contact pads painted on the surface of the samples and cured at $400^{\circ} \mathrm{C}$.

\section{Results and Discussion}

Figure 1 shows the XRD patterns of the YSZ/vNiO samples. All the diffraction peaks were indexed according to the cubic structure of both oxides, space group $F m \overline{3} m$, and no extra peaks due to any spurious phase were detected. Table I reports the main parameters of the calculated XRD patterns. The good quality of the Rietveld refinements is evidenced by the low values of the reliability factors $\chi^{2} \approx 2$ and $R_{\mathrm{Bragg}} \approx 3 \%$. The calculated volume fractions of the phases are within $\sim 3 \%$ of the nominal values, and the refined lattice parameters (a) of both oxides are in good agreement with previously reported data. ${ }^{15}$ The YSZ lattice parameter dependence on the $\mathrm{NiO}$ content, displayed on the inset of Fig. 1, shows no significant changes, indicating that no appreciable solid solution occurred at $1350^{\circ} \mathrm{C}$. If $\mathrm{Ni}^{2+}$ substitutes either for $\mathrm{Zr}^{4+}$ or $\mathrm{Y}^{3+}$ ions in the $\mathrm{YSZ}$ structure, a pronounced decrease in the lattice parameter would occur due to the smaller ionic radius of nickel. ${ }^{5,16}$ It was already reported that the $\mathrm{NiO}$ solubility limit in the cubic zirconia structure is $<5 \mathrm{~mol} \%(<8 \mathrm{vol} \%)$ for dense samples sintered at $1600^{\circ} \mathrm{C}$ for $4 \mathrm{~h} .{ }^{9}$ In the present study, sintering the prepared powders at a relatively lower temperature resulted in dense composite samples, as inferred from the measured relative densities. The composite densities were determined by the Archimedes method and the theoretical values were calculated by the rule of mixture using the reported density values of YSZ and NiO. The apparent density of the specimens was found to be $\sim 96 \%$ of the theoretical value.

SEM images of polished and thermally etched surfaces shown in Fig. 2 indicate that both phases are homogenously distributed in the composites. Specimens sintered at $1350^{\circ} \mathrm{C}$ for $1 \mathrm{~h}$ (Fig. $2 \mathrm{a}$ and b) were found to have estimated average grain size $\sim 800$ and $\sim 700 \mathrm{~nm}$ for $\mathrm{YSZ}$ and $\mathrm{NiO}$, respectively. In addition, the average grain size of both phases was observed to be nearly independent of the relative composition. The SEM images show that the average size of the $\mathrm{NiO}$ particles heat-treated at $450^{\circ} \mathrm{C}$ exhibited a large increase in size when sintered at $1350^{\circ} \mathrm{C}$, while pure YSZ samples sintered under similar conditions had an average grain size comparable to those found in the YSZ/NiO composites. ${ }^{19}$

The microstructural characterization of the $\mathrm{YSZ} / v \mathrm{NiO}$ composites revealed that the liquid mixture technique produced sinteractive powders, yielding dense samples formed by a homogeneous mixture of the oxides. The electrical properties were then investigated by impedance spectroscopy measurements. The $Z(\omega, T)$ data showed at least two semicircles in the whole frequency and temperature ranges studied. ${ }^{18}$ However, in this study the focus was on the total electrical resistance of the $\mathrm{YSZ} / v \mathrm{NiO}$ composite, which was obtained by fitting the low-frequency end of the impedance diagrams. The electrical conductivity $\sigma(T)$ of the composites was measured in a wide range of temperature, and Fig. 3 shows the $\sigma(T)$ dependence on the $\mathrm{NiO}$ content.

In addition, the transport mechanism of the composite was studied with the Arrhenius plots, shown in Fig. 4. As far as the electrical transport is concerned, YSZ is known to be an ionic conductor (ionic transference number $t_{\mathrm{I}} \approx 1$ ) with thermally activated transport of oxygen vacancies with an activation energy $\Delta E \approx 1 \mathrm{eV}$ over a wide range of both temperature and oxygen partial pressure $\left(p_{\mathrm{O}_{2}}\right) .{ }^{4}$ $\mathrm{NiO}$ is a p-type semiconductor, the charge carriers being the electron holes due to $\mathrm{Ni}$ vacancies. ${ }^{5,19} \mathrm{NiO}$ exhibits a discontinuity in the Arrhenius plots at a temperature close to the Néel temperature $\left(T_{\mathrm{N}} \approx 250^{\circ} \mathrm{C}\right)$, and the activation energies are $\Delta E \approx 0.7$ and $0.3 \mathrm{eV}$ for $T<T_{\mathrm{N}}$ and $T>T_{\mathrm{N}}$, respectively. ${ }^{5,19}$ The $\sigma(T)$ data at

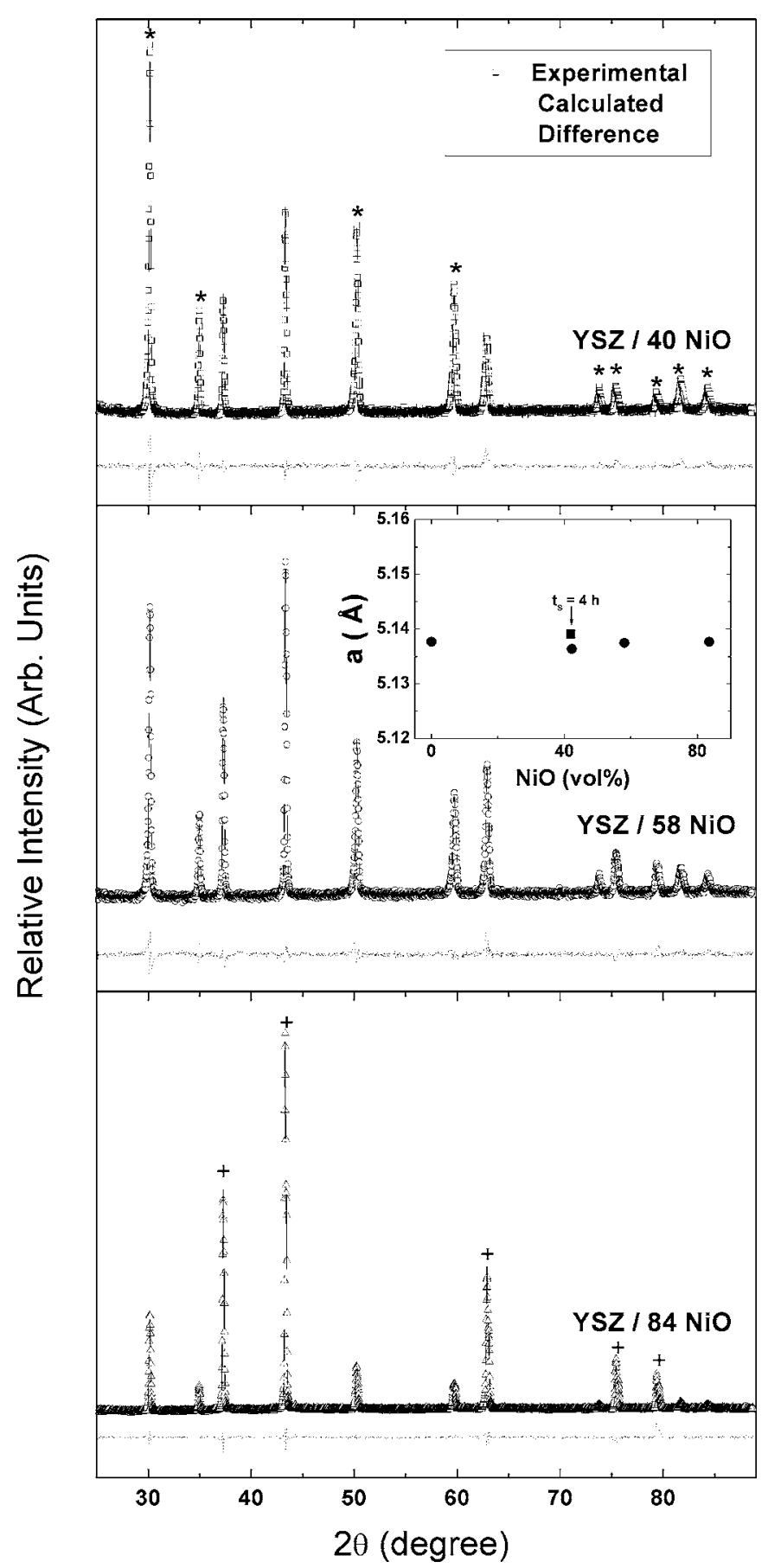

Figure 1. XRD patterns of $(1-v)\left(\mathrm{ZrO}_{2}: 8 \mathrm{~mol} \% \mathrm{Y}_{2} \mathrm{O}_{3}\right) / v \mathrm{NiO}$ samples with $v=40,58$, and 84 vol $\%$. The ${ }^{*}$ and + symbols indicate the YSZ and $\mathrm{NiO}$ main diffraction peaks, respectively. The experimental, calculated, and difference plots are shown. The inset shows the dependence of the calculated lattice parameter of cubic zirconia on the $\mathrm{NiO}$ content.

low temperatures $\left(T<400^{\circ} \mathrm{C}\right)$ shown in Fig. 3 indicated that the $\mathrm{NiO}$ content had a large influence on the electrical conductivity of the composite. At low temperatures, YSZ behaved as insulating particles and the $\sigma(T)$ increased three orders of magnitude from $v=0-23$ vol $\%$ at $T \approx 240^{\circ} \mathrm{C}$. This remarkable increase of $\sigma(T)$ is due to the increase in the density of electronic charge carriers from $\mathrm{NiO}$ and indicates that the percolation threshold was attained at $v \approx 20$ vol $\%$. The relatively low critical volume fraction may be attributed to the high dispersion and good connectivity of $\mathrm{NiO}$ par- 


\begin{tabular}{|c|c|c|c|c|c|}
\hline $\begin{array}{c}\text { Nominal } \\
\mathrm{NiO} \\
(\text { vol \%) }\end{array}$ & $\begin{array}{c}\text { YSZ } a \\
(\AA)\end{array}$ & $\begin{array}{c}\mathrm{NiO} a \\
(\AA)\end{array}$ & $\chi^{2}$ & $R_{\text {Bragg }}$ & $\begin{array}{c}\text { Calculated } \\
\mathrm{NiO} \\
(\mathrm{vol} \%) \\
\end{array}$ \\
\hline 40 & $5.1364(1)$ & $4.1888(1)$ & 2.7 & 4.0 & $41.5(2)$ \\
\hline 58 & $5.1375(1)$ & $4.1886(1)$ & 2.2 & 3.5 & 55.1(1) \\
\hline 84 & $5.1377(1)$ & $4.1790(1)$ & 2.3 & 3.4 & 84.9( \\
\hline
\end{tabular}

ticles in the YSZ matrix, as well as to the average grain size ratio of the two phases. ${ }^{12}$ It is interesting that the usually observed decrease in the electrical conductivity at low $\mathrm{NiO}$ content $(v \leqslant 10 \mathrm{vol} \%)$, ascribed to solid solution formation of $\mathrm{YSZ} / \mathrm{NiO}$ composites sintered at higher temperatures, is absent in the samples prepared by
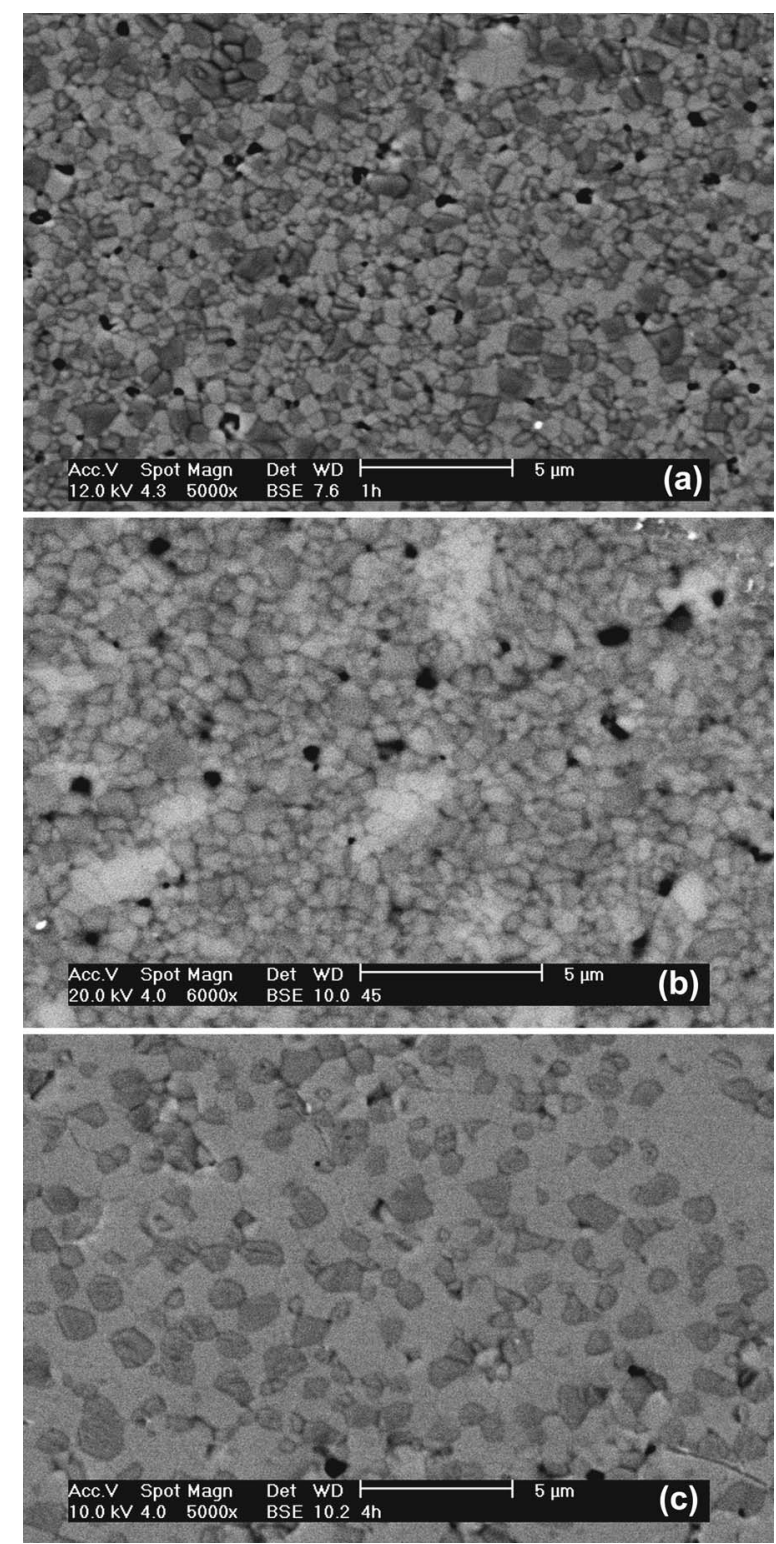

Figure 2. Backscattered SEM images of the $(1-v)$ $\left(\mathrm{ZrO}_{2}: 8 \mathrm{~mol} \% \mathrm{Y}_{2} \mathrm{O}_{3}\right) / v \mathrm{NiO}$ samples with $v=40(\mathrm{a})$ and $58(\mathrm{~b})$ sintered at $1350^{\circ} \mathrm{C} / 1 \mathrm{~h}$, and $v=40$ (c) sintered at $1350^{\circ} \mathrm{C} / 4 \mathrm{~h}$. The darker grains correspond to the $\mathrm{NiO}$.

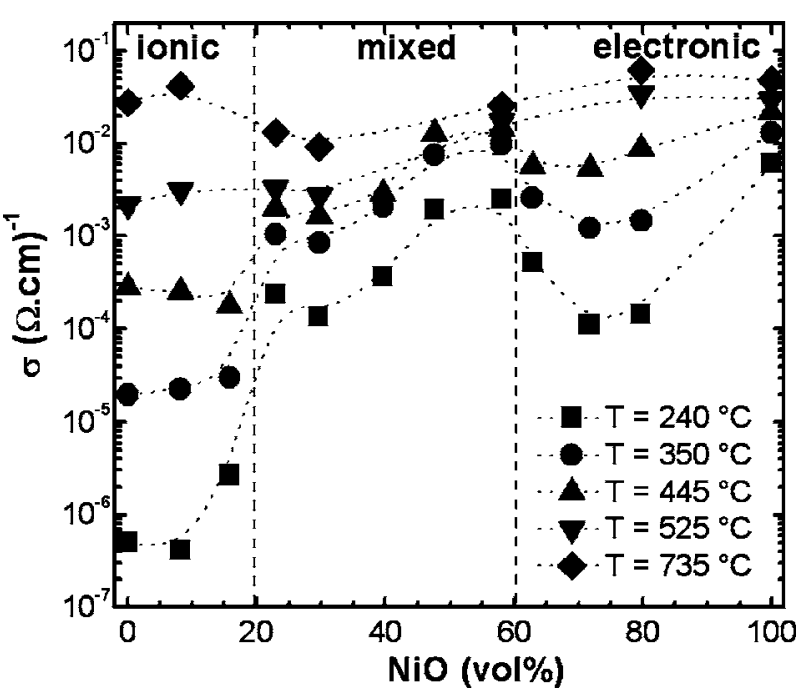

Figure 3. Electrical conductivity dependence on $\mathrm{NiO}$ content of $(1-v)$ $\left(\mathrm{ZrO}_{2}: 8 \mathrm{~mol} \% \mathrm{Y}_{2} \mathrm{O}_{3}\right) / v \mathrm{NiO}$ composite measured at different temperatures. The lines are guide for the eye.

the liquid mixture technique. ${ }^{5}$ As the $\mathrm{NiO}$ percolation threshold was attained at $v \approx 20 \mathrm{vol} \%$, the electrical transport of the specimens with $v<20$ vol \% is dominated by the ionic charge carriers of YSZ. In fact, the Arrhenius plots show that samples with $v<20$ vol \% exhibited a single thermally activated process in the whole temperature range with $\Delta E \approx 1 \mathrm{eV}$ (Fig. 4). However, samples with $v \approx 16$ vol \% showed $\Delta E \approx 0.7 \mathrm{eV}$, a value appreciably lower than the one of pure YSZ ionic conductor, as observed in Fig. $4 .^{5}$ At $v=23$ vol \% the discontinuity of the Arrhenius plot at $T_{\mathrm{N}} \approx 250^{\circ} \mathrm{C}$ was observed as a signature of the $\mathrm{NiO}$ transport behavior, further confirming the percolation of the semiconductor phase in the ionic matrix and indicating that samples with $v \approx 20$ vol $\%$ have mixed conductivity. Samples with $v \geqslant 20$ vol \% have $\Delta E$ close to the values previously reported for $\mathrm{NiO}$ in the two temperature ranges $\left(0.7 \mathrm{eV}\right.$ for $T<T_{\mathrm{N}}$ and $0.3 \mathrm{eV}$ for $T>T_{\mathrm{N}}$ ), as shown in Fig. 4. Further increasing the NiO content up to $v \approx 60 \mathrm{vol} \%$ resulted in increasing the electrical conductivity; the electrical transport properties of the samples in the $20<v<60$ vol \% range are believed to be due to both the ionic

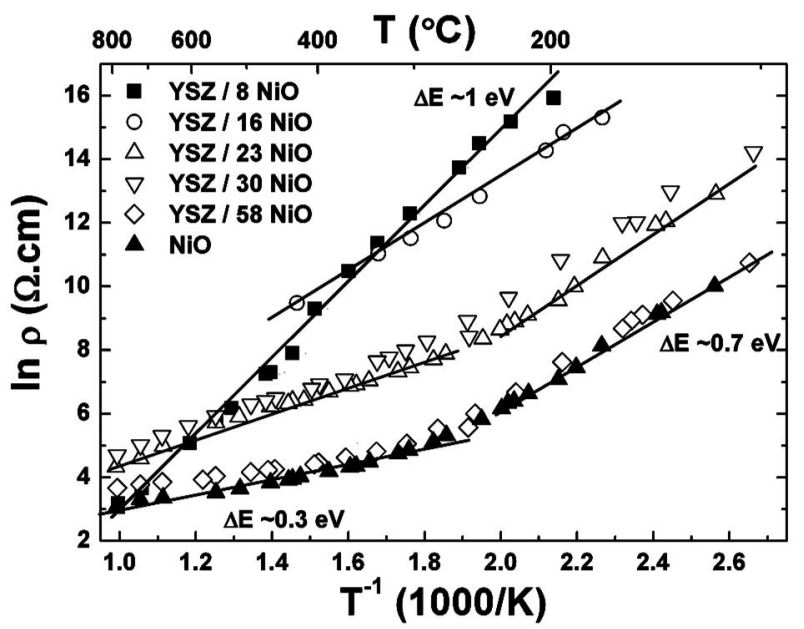

Figure 4. Arrhenius plots of the $(1-v)\left(\mathrm{ZrO}_{2}: 8 \mathrm{~mol} \% \mathrm{Y}_{2} \mathrm{O}_{3}\right) / v \mathrm{NiO}$ composites. 

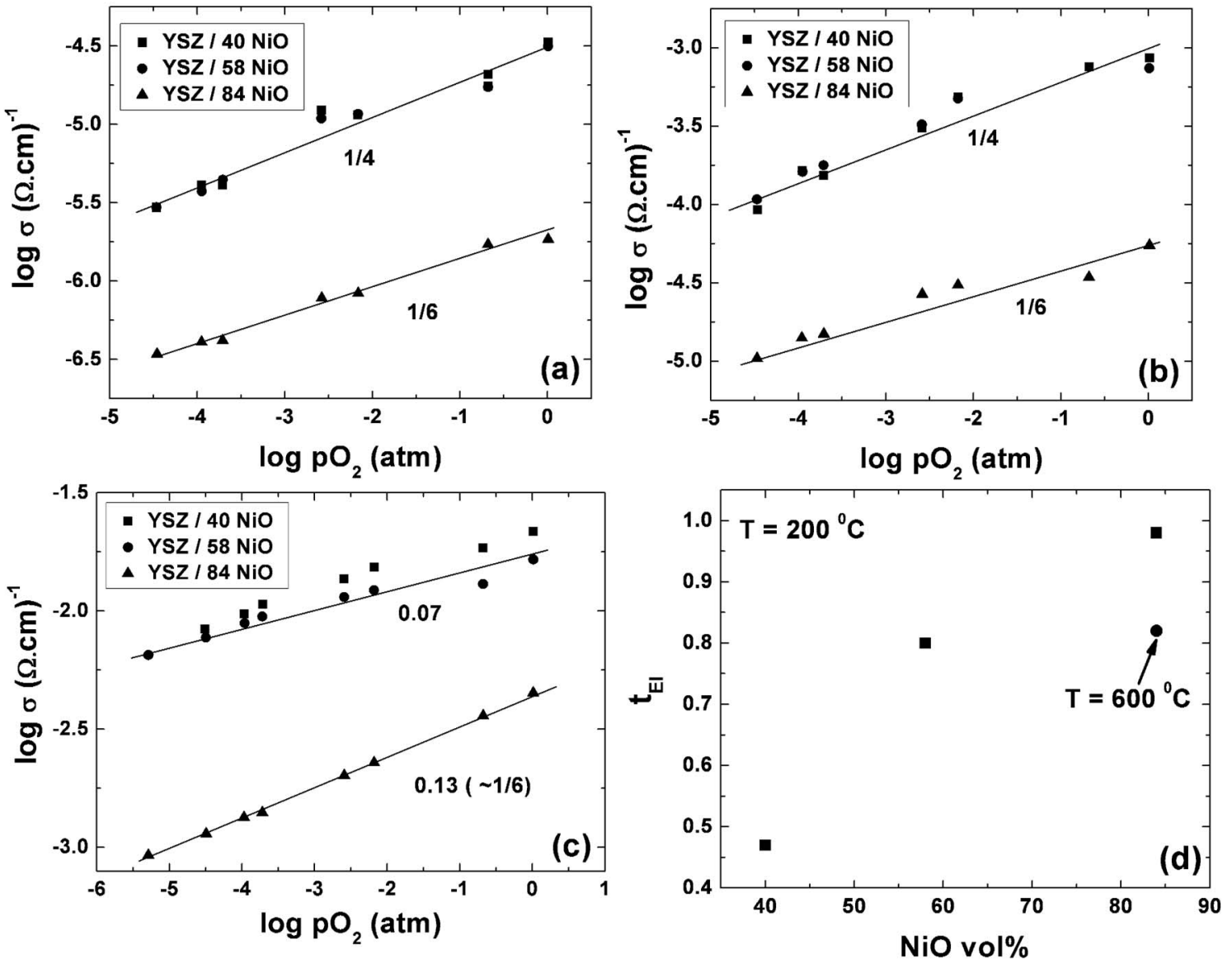

Figure 5. Electrical conductivity dependence on the oxygen partial pressure of $(1-v) \mathrm{ZrO}_{2}: 8$ mol $\% \mathrm{Y}_{2} \mathrm{O}_{3} / v$ NiO composites with $v=40$, 58, and 84 vol $\%$, measured at $200^{\circ} \mathrm{C}(\mathrm{a}), 300^{\circ} \mathrm{C}(\mathrm{b})$, and $600^{\circ} \mathrm{C}$ (c), and electronic transfer number dependence on the $\mathrm{NiO}$ content (d).

and electronic charge carriers, as observed at low temperatures $\left(T<400^{\circ} \mathrm{C}\right)$ in Fig. 3. The electrical transport data suggest that the enhanced $\mathrm{NiO}$ connectivity in the $\mathrm{YSZ} / \mathrm{NiO}$ composites, prepared by the liquid mixture technique, lead to electronic pathways at relatively lower semiconductor content than in other reported samples. Specimens with $\mathrm{NiO}$ content $v>60 \mathrm{vol} \%$ exhibited a decrease in the electrical conductivity down to a minimum at $v \approx 80 \mathrm{vol} \%$. In these specimens with large $\mathrm{NiO}$ content the transport was mainly due to the electron holes, while YSZ grains acted as insulating inclusions at low temperatures. However, the transport properties of the composites were strongly affected by the temperature due to the different activation energies of the electronic $(\sim 0.3 \mathrm{eV})$ and ionic $(\sim 1 \mathrm{eV})$ conductors at high temperatures. With increasing temperature, the higher $\Delta E$ value of YSZ promoted a high conductivity of the $\mathrm{O}^{2-}$ ions, and $\sigma\left(T>500^{\circ} \mathrm{C}\right)$ of the composite samples were of the same order of magnitude in the whole $\mathrm{NiO}$ concentration range. In fact, samples with $v<20$ vol $\%$ and $v>60$ vol $\%$ exhibited the most pronounced increase in the electrical conductivity with increasing temperature, while samples in the mixed transport range were considerably less influenced by temperature (Fig. 3).

The combined results shown in Fig. 3 and 4 allowed us to estimate three different transport characteristics of the YSZ $/ v \mathrm{NiO}$ composites: for $v<20$ vol \% the composites were essentially ionic conductors, for $20<v<60$ vol $\%$ the composites were MIECs, and for $v>60$ vol \% the transport was predominately due to electron holes. ${ }^{6,18}$ This behavior was further confirmed by the analysis of the electrical conductivity data taken under different oxygen partial pressures. Figure 5a-c shows the electrical conductivity dependence on the $p_{\mathrm{O}_{2}}$ of $v=40,58$, and $84 \mathrm{vol} \%$ samples measured at 200,300 , and $600^{\circ} \mathrm{C}$, respectively. These findings demonstrated that the samples exhibited the expected linear behavior of a p-type semiconductor. In addition, by assuming that the phases are connected in parallel for $\mathrm{NiO}$ concentrations above the percolation threshold, the linear dependence of $\sigma$ on the $p_{\mathrm{O}_{2}}$ was fitted according to the relation $\sigma=A+B p_{\mathrm{O}_{2}}^{x}$, where $A$ is the $p_{\mathrm{O}_{2}}$-independent ionic conduction, $B$ is the electronic conduction, and $x$ is the exponent giving the

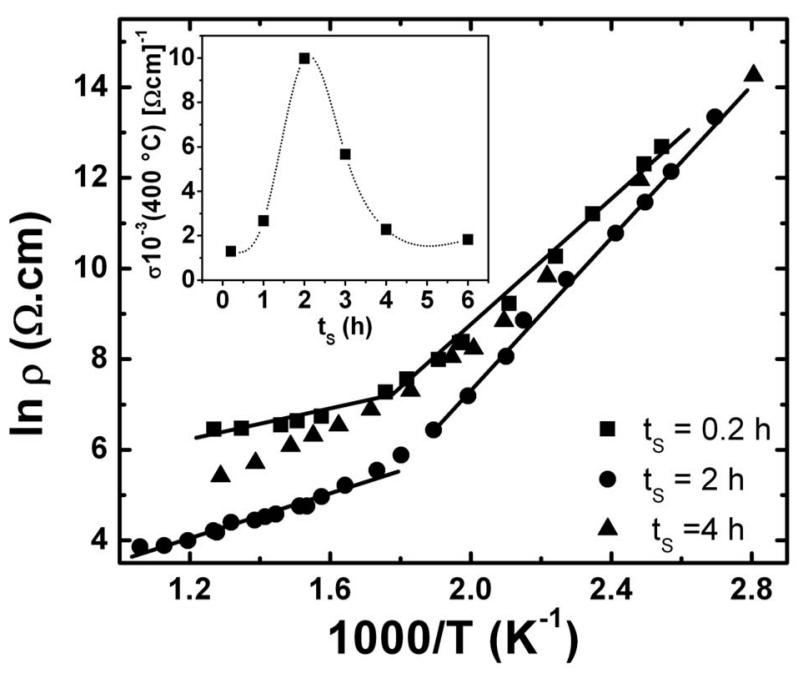

Figure 6. Arrhenius plots of the $\left(\mathrm{ZrO}_{2}: 8 \mathrm{~mol} \% \mathrm{Y}_{2} \mathrm{O}_{3}\right) / 40$ vol $\% \mathrm{NiO}$ composite sintered at $1350^{\circ} \mathrm{C}$ for different times. The inset shows the dependence of the electrical conductivity measured at $400^{\circ} \mathrm{C}$ on the sintering time. 


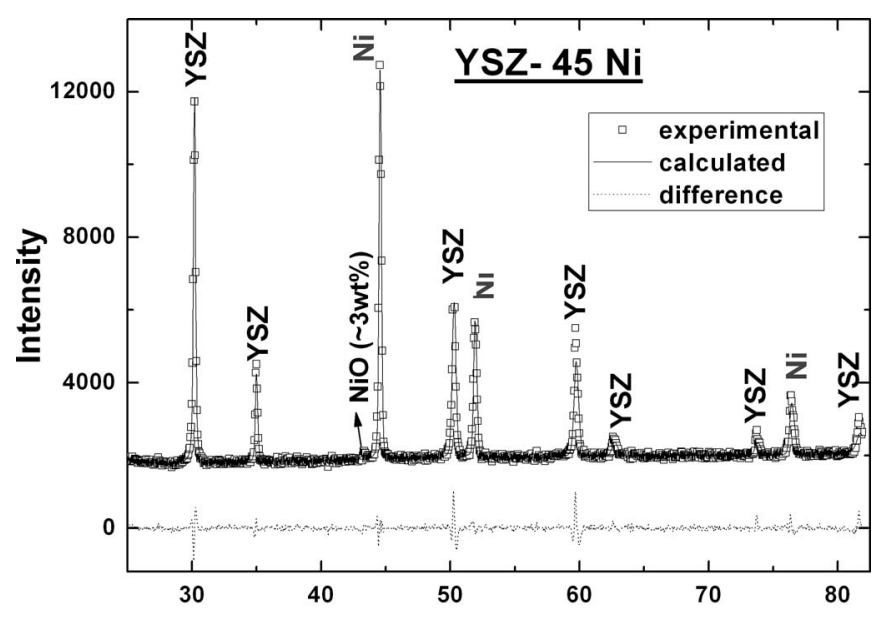

$2 \theta$ (degree)

Figure 7. Experimental and calculated XRD patterns of the reduced cermet $\left(\mathrm{ZrO}_{2}: 8 \mathrm{~mol} \% \mathrm{Y}_{2} \mathrm{O}_{3}\right) / 45 \mathrm{vol} \% \mathrm{Ni}$ and the difference plot.

$p_{\mathrm{O}_{2}}$ dependence of the semiconductor phase. For measuring temperatures 200 and $300^{\circ} \mathrm{C}$, both samples $v=40$ and $58 \mathrm{vol} \%$ had a $p_{\mathrm{O}_{2}}^{1 / 4}$-dependence and the $v=84$ vol \% sample exhibited a less pronounced $p_{\mathrm{O}_{2}}$ dependence, being the fitted exponent $x=1 / 6$. The electronic transport in $\mathrm{NiO}$ has been already studied, and both $p_{\mathrm{O}_{2}}$ dependences $1 / 4$ and $1 / 6$ have been measured. It has been reported that the exponent $x$ depends on the ionization state of the $\mathrm{Ni}$ vacancies. ${ }^{20}$ When the concentration of single-ionized $\mathrm{Ni}$ vacancies is larger than the double-ionized one, the $p_{\mathrm{O}_{2}}$ dependence is $1 / 4$, and when double-ionized vacancies predominate, the electron hole concentration is proportional to $p_{\mathrm{O}}^{1 / 6}$. In fact, high-purity $\mathrm{NiO}$ single crystals were found to have a $p_{\mathrm{O}_{2}}^{1 / 6}$ dependence and for less pure $\mathrm{NiO}$ specimens a $1 / 4$ power has been observed. ${ }^{20}$ Thus, the results here presented suggested that the samples with high $\mathrm{NiO}$ content have a higher content of doubly-charged $\mathrm{Ni}$ vacancies and the mixture with YSZ seems to yield a $p_{\mathrm{O}_{2}}$ dependence close to the $1 / 4$ power, in agreement with previously reported data. ${ }^{5}$ Increasing the measuring temperature up to $600^{\circ} \mathrm{C}$ caused a decrease in the electrical conductivity dependence on the $p_{\mathrm{O}_{2}}$, and the fitted exponents were lower than those found at low temperatures (Fig. 5c). Such an effect was more pronounced in samples with larger amounts of the ionic phase and indicates that the effective fraction of ionic charge carriers increased when the thermal energy activated the $p_{\mathrm{O}_{2}}$-independent transport of the YSZ oxygen ions, in agreement with the results of Fig. 3. The electronic transfer number $t_{\mathrm{El}}$ was estimated by using $t_{\mathrm{El}}=1-t_{I}=B p_{\mathrm{O}_{2}}^{x} / \sigma$; Fig. $5 \mathrm{~d}$ shows the $t_{\mathrm{El}}$ values measured at $200^{\circ} \mathrm{C}$. As expected, increasing the $\mathrm{NiO}$ content increased the electronic transport from $t_{\mathrm{El}} \approx 45-98 \%$ for the samples $v=40$ and $84 \mathrm{vol} \%$, respectively, further indicating the mixed conduction of the samples in the $20<v<60$ vol \% range and the predominant

Table II. Rietveld refined parameters of the reduced cermets. The atomic positions and thermal factors were fixed according to the values reported in the crystallographic files ICSD no. 75316 (YSZ) and 44767 (Ni).

\begin{tabular}{cccccc}
$\begin{array}{c}\text { Nominal } \\
\mathrm{Ni} \\
(\mathrm{vol} \%)\end{array}$ & $\begin{array}{c}\text { YSZ } a \\
(\AA)\end{array}$ & $\begin{array}{c}\mathrm{Ni} a \\
(\AA)\end{array}$ & $\chi^{2}$ & $R_{\text {Bragg }}$ & $\begin{array}{c}\text { Calculated } \\
\mathrm{Ni} \\
(\text { vol \%) }\end{array}$ \\
\hline 28 & $5.1402(1)$ & $3.5274(1)$ & 2.1 & 3.1 & $28.2(3)$ \\
45 & $5.1405(1)$ & $3.5277(1)$ & 3.2 & 3.8 & $40.3(2)$
\end{tabular}

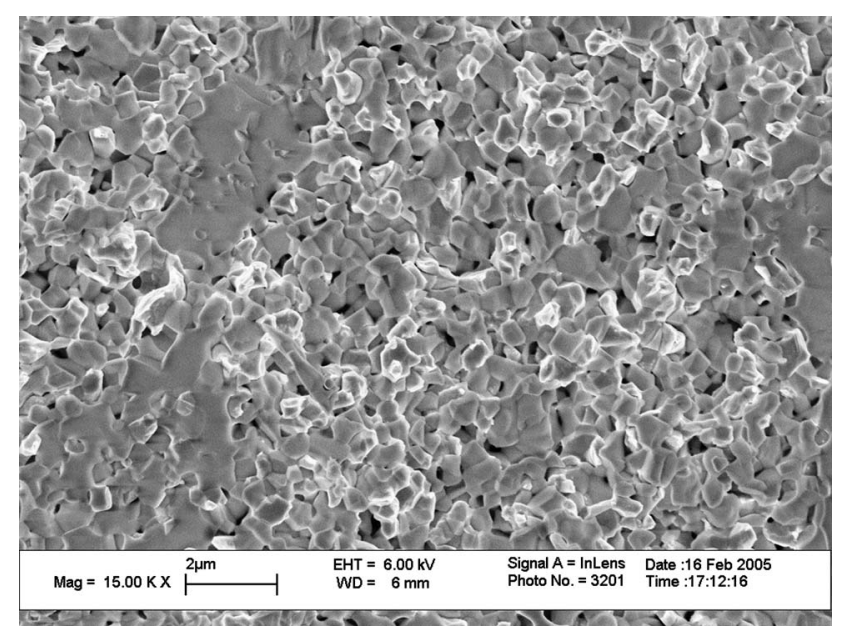

Figure 8. SEM of the fractured surface of the $\left(\mathrm{ZrO}_{2}: 8 \mathrm{~mol} \% \mathrm{Y}_{2} \mathrm{O}_{3}\right) / 28$ vol \% Ni sintered for $2 \mathrm{~h}$.

electronic conduction in the sample $v=84$ vol $\%$. In addition, for increasing temperatures, the electronic transfer number decreased, and at $600^{\circ} \mathrm{C}$ the $t_{\mathrm{El}}$ of the sample $v=84 \mathrm{vol} \%$ decreased from $\sim 98$ to $80 \%$, indicating that the transport due to $\mathrm{O}^{-2}$ in YSZ became relevant at high temperatures even for relatively low volume fraction $(Y S Z \approx 16$ vol \%). The above results indicated that both the relative phase volume fraction and the temperature play important roles in the transport properties of the YSZ/NiO composites.

The microstructure is also considered important for determining the transport properties of a composite. Thus, to further evaluate the electrical properties in the mixed conduction range, YSZ/NiO specimens were sintered at $1350^{\circ} \mathrm{C}$ for different sintering times, $t_{S}$. Samples with $v=40$ and $58 \mathrm{vol} \%$ were sintered at $1350^{\circ} \mathrm{C}$ for $0.2 \mathrm{~h} \leqslant t_{S} \leqslant 6 \mathrm{~h}$; the discussion is here focused on the $v=40 \mathrm{vol} \%$ sample, which is close to the percolation threshold and exhibited a more pronounced dependence on $t_{S}$. The XRD data show that the YSZ lattice parameters did not depend on the sintering time, further indicating that no solid solution between the oxides occurred at $1350{ }^{\circ} \mathrm{C}$ (see inset of Fig. 1). The relative density was found to continuously increase from $\sim 82$ to $\sim 97 \%$ of the theoretical value when the sintering time $t_{S}$ increased from 0.2 to $2 \mathrm{~h}$,

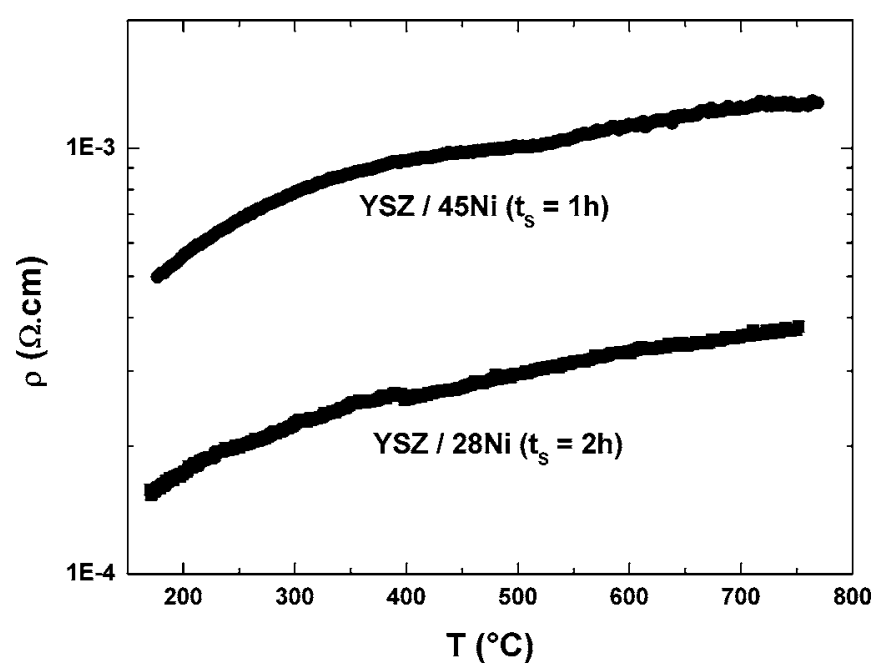

Figure 9. dc electrical resistivity dependence on temperature for the $\left(\mathrm{ZrO}_{2}: 8 \mathrm{~mol} \% \mathrm{Y}_{2} \mathrm{O}_{3}\right) / v$ Ni cermets for $v=28$ and 45 vol $\%$ sintered for 2 and $1 \mathrm{~h}$, respectively. 
Table III. Estimated values of $\mathrm{NiO}$ and $\mathrm{Ni}$ relative volume fraction, electrical conductivity, and the respective measuring temperatures of YSZ/NiO (Ni) composites prepared by different methods reported in the literature.

\begin{tabular}{|c|c|c|c|c|c|}
\hline $\mathrm{NiO}(\operatorname{vol} \%)$ & $\mathrm{Ni}(\operatorname{vol} \%)$ & Preparation method & $\begin{array}{c}\sigma \\
(\Omega \mathrm{cm})^{-1}\end{array}$ & $\begin{array}{c}T \\
\left({ }^{\circ} \mathrm{C}\right)\end{array}$ & Reference \\
\hline 23 & - & Modified liquid mixture & $3.3 \times 10^{-3}$ & 450 & This work \\
\hline 25 & - & Aqueous coassembly & $2.9 \times 10^{-5}$ & 450 & 7 \\
\hline 40 & - & Modified liquid mixture & $9.1 \times 10^{-3}$ & 400 & This work \\
\hline 40 & - & Solid-state mixture & $6.3 \times 10^{-5}$ & 400 & 5 \\
\hline 48 & - & Modified liquid mixture & $1.3 \times 10^{-2}$ & 450 & This work \\
\hline 52 & - & Modified Pechini & $2.0 \times 10^{-4}$ & 450 & 21 \\
\hline - & 28 & Modified liquid mixture & $2.8 \times 10^{3}$ & 700 & This work \\
\hline- & 30 & Combustion synthesis & 77 & 700 & 8 \\
\hline- & $\sim 27$ & Polymer precursors & $3.4 \times 10^{2}$ & 700 & 23 \\
\hline- & 40 & Coat-mix & from 78 to $4.0 \times 10^{3}$ & 800 & 24 \\
\hline
\end{tabular}

while for $t_{S} \geqslant 2 \mathrm{~h}$ the relative density remained nearly constant. The SEM images revealed that increasing $t_{S}$ increased the average grain size of both YSZ and NiO, being $\sim 1.5$ and $\sim 1.2 \mu \mathrm{m}$, respectively, as displayed in Fig. 2c. It was already reported that $\mathrm{NiO}$ particles may inhibit YSZ grain growth; however, probably due to the initial average particle size of the powders produced by the liquid mixture technique, such an effect was not observed. ${ }^{21}$ By comparing the SEM images of the samples sintered for 1 and $4 \mathrm{~h}$ (Fig. 2a and c), it is important to observe that increasing $t_{S}$ resulted in a larger separation between $\mathrm{NiO}$ grains. The microstructural features of the isothermal sintering at $1350^{\circ} \mathrm{C}$ have a strong influence on the electrical properties, as observed in Fig. 6. The Arrhenius plots of the samples with $v=40 \mathrm{vol} \%$ sintered for different times exhibited the same behavior previously discussed; however, at high temperatures $\left(T>T_{\mathrm{N}}\right)$ a significant dependence on the sintering time was observed (see inset of Fig. 6). The electrical conductivity $\sigma\left(T=400^{\circ} \mathrm{C}\right)$ increased with increasing $t_{S}$ up to $2 \mathrm{~h}$, reaching a maximum due to the decrease in porosity. Further increasing $t_{S}$ $>2 \mathrm{~h}$ resulted in a decrease of $\sigma$ of an order of magnitude, which may be correlated with the larger separation of $\mathrm{NiO}$ grains observed in Fig. 2. This finding evidenced that the percolation of charge carriers in MIEC composites can also be controlled by the relative grain size of both phases.

In order to investigate the suitability of the liquid mixture technique and the influence of the precursor composite properties on the SOFC anode cermet, the composites in the mixed conduction region with 40 and 58 vol $\% \mathrm{NiO}$ and sintered for $t_{S}=2$ and $1 \mathrm{~h}$, respectively, were reduced under $\mathrm{H}_{2}$ flow at $550^{\circ} \mathrm{C}$. The resulting cermets with nominal Ni content 28 and $45 \mathrm{vol} \%$ were analyzed by XRD, as shown in Fig. 7. The XRD data were refined by the Rietveld method, and Table II reports the main calculated parameters. The calculated lattice parameters of both phases are similar to the values reported in the literature, and the Ni volume fractions estimated were slightly smaller than the nominal values. This might be due to the relatively low temperature used in the reduction that resulted in a small fraction of remaining $\mathrm{NiO}(\leqslant 3 \mathrm{wt} \%$, as inferred from Rietveld refinements) in the cermet. Figure 8 shows, as an example of the microstructure of the reduced samples, a representative region of a typical fractured surface of the YSZ/28 Ni cermet sintered for $2 \mathrm{~h}$. It is possible to observe that the reduction at $550^{\circ} \mathrm{C}$ did not cause any significant increase in the particle size of the metallic phase (brighter regions in Fig. 8) when compared to the $\mathrm{NiO}$ particles (darker regions in Fig. 2). In addition, this micrograph suggests the presence of a larger porosity (cf. Fig. 2) resulting from the $\mathrm{NiO}$ reduction. However, a clear percolation path of the metallic phase was seen through the sample, as inferred from the electrical properties of the cermet. Figure 9 shows the temperature dependence of the electrical resistivity of the samples with 28 and 45 vol \% Ni sintered for 2 and $1 \mathrm{~h}$, respectively. The electrical resistivity data exhibited essentially the same behavior as pure $\mathrm{Ni}$, with the characteristic change of slope associated with the Curie temperature at
$T \approx 350^{\circ} \mathrm{C}$, but shifted to higher resistivity values due to the presence of both YSZ and pores. ${ }^{22}$ However, both samples showed larger values of electrical conductivity at lower Ni concentrations than data usually reported for this cermet. ${ }^{8,23,24}$ In addition, the cermet with 28 vol \% Ni (former $v=40$ vol $\% \mathrm{NiO}$ ) had smaller electrical resistivity values, attributed to both the higher electrical conductivity of the precursor composite and to the lower porosity after reduction of samples with lower volume fraction of NiO. These results confirmed that the control of the microstructural properties of the precursor composite is an important factor to produce cermets with high electrical conductivity at low Ni contents.

For comparison purposes, the present electrical conductivity values along with reported ones for YSZ/NiO composites and YSZ/Ni cermets prepared by other techniques are displayed in Table III. The differences observed in the data referenced in Table III can be ascribed to the strong dependence of the electrical conductivity on the preparation method. In order to attain high density, sintering temperatures higher than the ones used in this work are usually required. Sintering at higher temperatures is likely to promote the formation of solid solution between the oxides, which is expected to result in lower values of the electrical conductivity.

\section{Conclusions}

In summary, YSZ/NiO composites have been prepared by a liquid mixture method, which resulted in homogenous powders with high sinterability. The relatively low sintering temperature inhibited solid solution formation between the two oxides. The $\mathrm{NiO}$ concentration ranges where the main charge carriers are ionic, mixed, and electronic were estimated. The effectiveness of the described preparation method is evidenced by the high values of both the relative density and the electrical conductivity of the composites at low $\mathrm{NiO}$ contents, indicating the good connectivity of the semiconductor particles. The results show that the careful design of a mixed ionicelectronic composite for optimized transport properties must take into consideration the relative composition of the phases, the microstructural features, and operation temperature of the electrochemical device. The suitable design of the YSZ/NiO composite allowed for the preparation of cermets with relatively low concentration of $\mathrm{Ni}$ and high electrical conductivity, which is an important feature concerning the application of this cermet as SOFC anodes.

\section{Acknowledgments}

This work was partially supported by the Brazilian agencies FAPESP (98/14324-0, 99/10798-0, and 03/08793-8) and CNPq (306496/88-7, 300934/94-7, 301661/2004-9); and by the Italian Ministry of Education, University and Research (MIUR) under the framework of an FISR project. Thanks are also due to Dr. E. V. Spinacé (IPEN) and Dr. R. F. Jardim (IF-USP) who helped with the cermet fabrication and dc electrical measurements, respectively.

Fundação de Amparo à Pesquisa do Estado de São Paulo assisted in meeting the publication costs of this article. 


\section{References}

1. P. Knauth and H. L. Tuller, J. Am. Ceram. Soc., 85, 1654 (2002).

2. A. Thursfield and I. S. Metcalfe, J. Mater. Chem., 14, 2475 (2004).

3. I. Reiss, Solid State Ionics, 157, 1 (2003)

4. N. Q. Minh, J. Am. Ceram. Soc., 76, 563 (1993).

5. Y. M. Park and G. M. Choi, J. Electrochem. Soc., 146, 883 (1999).

6. Y. M. Park and G. M. Choi, Solid State Ionics, 120, 265 (1999).

7. M. Mamak, N. Coombs, and G. Ozin, Adv. Funct. Mater., 11, 59 (2001).

8. U. Anselmi-Tamburini, G. Chiodelli, M. Arimondi, F. Maglia, G. Spinolo, and Z. A. Munir, Solid State Ionics, 110, 35 (1998).

9. A. Kuzjukevics and S. Linderoth, Solid State Ionics, 93, 255 (1997)

10. H. Kondo, T. Sekino, T. Kusunose, T. Nakayama, Y. Yamamoto, and K. Niihara, Mater. Lett., 57, 1624 (2003).

11. N. F. Uvarov, Solid State Ionics, 136, 1267 (2000).

12. D. S. McLachlan, M. Blaszkiewicz, and R. E. Newnham, J. Am. Ceram. Soc., 73, 2187 (1990).

13. V. Esposito, C. D'Ottavi, S. Ferrari, S. Licoccia, and E. Traversa, in SOFC-VIII, S. C. Singhal and M. Dokiya, Editors, PV 2003-07, p. 643, The Electrochemical
Society Proceedings Series, Pennington, NJ (2003).

14. M. C. Steil, F. C. Fonseca, Y. V. França, J. F. Q. Rey, E. N. S. Muccillo, and R. Muccillo, Ceramica (Sao Paulo, Braz.), 48, 146 (2002).

15. R. P. Ingel and D. Lewis III, J. Am. Ceram. Soc., 69, 325 (1986).

16. R. D. Shannon, Acta Crystallogr., Sect. A: Cryst. Phys., Diffr., Theor. Gen. Crystallogr., A32, 751 (1976).

17. F. C. Fonseca and R. Muccillo, Solid State Ionics, 131, 301 (2000).

18. V. Esposito, D. Z. de Florio, F. C. Fonseca, E. N. S. Muccillo, R. Muccillo, and E. Traversa, J. Eur. Ceram. Soc., 25, 2637 (2005)

19. M. W. Vernon and M. C. Lovell, J. Phys. Chem. Solids, 27, 1125 (1966).

20. C. M. Osburn and R. W. West, J. Phys. Chem. Solids, 32, 1331 (1971).

21. P. Durán, J. Tartaj, F. Capel, and C. Moure, J. Eur. Ceram. Soc., 23, 2125 (2003).

22. L. Gmelin, Gmelin Handbuch Der Anorganischen Chemie, Ni [A II], p. 355, Springer-Verlag, New York (1974)

23. V. Petrovsky, T. Suzuki, P. Jasinski, and H. U. Anderson, Electrochem. Solid-State Lett., 8, A341 (2005).

24. F. Tietz, F. J. Dias, D. Simwonis, and D. Stöver, J. Eur. Ceram. Soc., 20, 1023 (2000). 